\title{
Kesepian dan Nomophobia pada Mahasiswa Perantau
}

\section{Loneliness and Nomophobia in Sojourn College Students}

\author{
Zihan Fahira', Zaujatul Amna ${ }^{2}$, Marty Mawarpury33, Syarifah Faradina ${ }^{4}$ \\ 1,2,3,4Program Studi Psikologi, Fakultas Kedokteran, Universitas Syiah Kuala
}

\begin{abstract}
The use of smartphones as a diversion from loneliness can trigger the emergence of nomophobia. This study aimed to determine the relationship between loneliness and nomophobia in regional college students at Syiah Kuala University. This study used a quantitative approach with the correlation method. The technique of determining the sample was purposive sampling with a total sample of 513 regional college students (157 men and 356 women) who actively studied at Syiah Kuala University, came from outside Banda Aceh, and not lived with parents or family relatives. UCLA Loneliness Scale (Version 3) and Nomophobia Questionnaire (NMP-Q) were used as instruments in collecting research data. The analysis methods used were descriptive statistics and product moment correlation technique. The analysis of the research data indicated that there is a positive and significant relation between loneliness and nomophobia in sojourn college students at Syiah Kuala University $(r=0.094$, $p=0.034)$. This means that the higher the loneliness, the higher the nomophobia. Otherwise the lower the loneliness, the lower the nomophobia.
\end{abstract}

Keywords: loneliness; nomophobia; smartphone; sojourn college student

Abstrak. Penggunaan smartphone sebagai upaya pengalihan dari rasa kesepian dapat memicu munculnya nomophobia. Penelitian ini bertujuan untuk mengetahui hubungan antara kesepian dengan nomophobia pada mahasiswa perantau di Universitas Syiah Kuala. Penelitian ini menggunakan pendekatan kuantitatif dengan metode korelasi. Teknik penentuan sampel menggunakan purposive sampling dengan jumlah sampel sebanyak 513 mahasiswa perantau (terdiri dari 157 laki-laki dan 356 perempuan) yang aktif kuliah di Universitas Syiah Kuala yang berasal dari luar Banda Aceh dan tidak tinggal bersama orang tua atau kerabat keluarga. UCLA Loneliness Scale (Version 3) dan Nomophobia Questionnaire (NMP-Q) digunakan sebagai instrumen dalam mengumpulkan data penelitian. Analisis menggunakan statistik deskriptif dan teknik korelasi Product Moment. Hasil analisis penelitian menunjukkan bahwa terdapat hubungan yang positif dan signifikan antara kesepian dengan nomophobia pada mahasiswa perantau di Universitas Syiah Kuala $(r=0,094 ; p=0,034)$. Hal ini dapat diartikan bahwa semakin tinggi kesepian maka semakin tinggi nomophobia, sebaliknya semakin rendah kesepian maka semakin rendah nomophobia.

Kata kunci: kesepian; mahasiswa perantau; nomophobia; smartphone

Mahasiswa perantau mengalami berbagai perbedaan yang harus dihadapi di lingkungan barunya (Ridha, 2018). Dewi (2016) menemukan dalam penelitiannya bahwa mahasiswa rantau di Universitas Syiah Kuala Banda Aceh cenderung kesulitan membangun hubungan baru karena kurang mampu beradaptasi dengan perbedaan budaya. Kondisi 
berada jauh dengan keluarga yang dialami mahasiswa perantau dapat memicu munculnya kesepian (Nejad et al., 2013). Hal senada juga dijelaskan oleh Hidayati (2016) bahwa berpisah atau berada jauh dengan keluarga dan teman dekat adalah salah satu faktor munculnya kesepian.

Peplau dan Perlman (1982) menyebutkan kesepian sebagai suatu perasaan dan kondisi yang tidak menyenangkan yang berasal dari ketidaksesuaian antara pengalaman dan harapan dalam hubungan bersama orang lain, baik secara kuantitatif (jumlah teman yang diharapkan) maupun kualitatif (kualitas hubungan yang diharapkan). Konsep teori kesepian yang dijelaskan Perlman dan Peplau merupakan perspektif kognitif yang dikembangkan dari hasil penelitian yang dilakukan terhadap individu normal (tidak ada gangguan patologis), sedangkan perspektif lainnya yaitu psikodinamika, existential, phenomenological, privacy, systems, sociological, dan interactionistic dikembangkan berdasarkan hasil terapi pada pasien atau clinical work, social analysis, dan tinjauan literatur.

Berdasarkan hasil penelitian Saputri et al. (2012) menunjukkan bahwa sebanyak $60 \%$ mahasiswa perantau mengalami kesepian kategori tinggi. Leung (2008) menjelaskan bahwa individu yang mengalami social isolation cenderung mengalihkan aktivitas atau menghabiskan waktu dengan smartphone untuk membantu mengurangi kesepian. Hal yang sama juga dijelaskan Bian dan Leung (2014) yang menyebutkan bahwa rasa kesepian menjadi salah satu penyebab individu berinteraksi melalui smartphone secara berlebihan. Kebiasaan menggunakan smartphone dengan tujuan untuk mengalihkan rasa kesepian dapat menimbulkan ketergantungan pada smartphone. Hal senada juga ditemukan dalam hasil penelitian SecurEnvoy (2012) bahwa penggunaan smartphone yang berlebihan cenderung menyebabkan seseorang mengalami ketergantungan dan memicu nomophobia.

Secara definisi, Yildirim dan Correia (2015) menjelaskan nomophobia sebagai fobia dari hasil interaksi antara manusia dengan teknologi informasi dan komunikasi, ditandai dengan munculnya ketakutan tidak rasional karena tidak dapat menggunakan ponsel atau smartphone dan layanan yang ditawarkannya. King et al. (2010) menjelaskan individu yang mengalami nomophobia cenderung cemas, berkeringat, gemetar, peningkatan denyut jantung, dan serangan panik ketika berjauhan dengan smartphone. Yildirim dan Correia menambahkan bahwa ciri-ciri individu yang mengalami nomophobia berupa cemas dan sedih ketika tidak dapat menggunakan smartphone. Tahun 2008 merupakan tahun di mana pertama kali munculnya istilah nomophobia yaitu dalam penelitian yang dilaksanakan oleh kantor pos di United Kingdom untuk mengetahui kecemasan para pengguna ponsel (Securenvoy, 2012). Laporan studi kasus mengenai nomophobia pertama kali diteliti oleh King et al. (2010) terhadap pasien agoraphobia yang mengacu pada DSMIV-TR.

Mansyur (2018) menemukan bahwa tingkat persentase nomophobia berat lebih banyak terjadi pada kelompok usia 18-21 tahun daripada kelompok usia 22-39 tahun pada 
masyarakat Aceh. Penelitian senada juga dilakukan Fitriana (2018) yang mengungkapkan bahwa kecenderungan nomophobia pada mahasiswa di Universitas Syiah Kuala yaitu sebesar 49\%. Dijelaskan lebih lanjut oleh Yuwanto (2010) bahwa faktor situasional seperti kesepian dan faktor sosial yaitu keinginan membangun interaksi dengan individu lain termasuk dalam faktor pemicu munculnya nomophobia. Ramaita et al. (2019) menambahkan bahwa nomophobia terjadi karena individu menggunakan smartphone sebagai pengalihan dari rasa kesepian.

Beberapa penelitian terdahulu membuktikan bahwa kesepian dan nomophobia memiliki korelasi positif yang signifikan, diantaranya yaitu penelitian Ozdemir et al. (2018) yang menemukan bahwa semakin tinggi tingkat kesepian, maka semakin tinggi tingkat nomophobia pada mahasiswa. Lebih lanjut, penelitian Gezgin et al. (2018) menemukan bahwa kesepian berkorelasi secara positif dan juga sebagai prediktor munculnya nomophobia. Sesuai dengan latar belakang, mahasiswa rantau mengalami kesepian karena kesulitan berinteraksi di lingkungan baru serta tingginya persentase nomophobia pada mahasiswa Universitas Syiah Kuala yaitu sebesar 49\%. Oleh karena itu, penelitian ini dilakukan dengan tujuan untuk mengkaji hubungan antara kesepian dan nomophobia pada mahasiswa perantau di Universitas Syiah Kuala Banda Aceh. Adapun penelitian mengenai kesepian dan nomophobia pada mahasiswa perantau belum pernah dilakukan di Aceh.

\section{Metode}

Penelitian ini merupakan penelitian kuantitatif dengan desain penelitian korelasi. Sampel penelitian ini adalah 513 mahasiswa perantau (157 laki-laki dan 356 perempuan) yang dipilih menggunakan teknik purposive sampling. Kriteria sampel penelitian yaitu: a. Mahasiswa perantau laki-laki dan perempuan yang masih aktif kuliah di Universitas Syiah Kuala; b. Memiliki smartphone; c. Berasal dari luar Banda Aceh; d. Tidak tinggal bersama orang tua atau kerabat keluarga. Pengumpulan data menggunakan dua skala yang telah melewati proses uji coba terhadap mahasiswa aktif di Banda Aceh. Skala yang digunakan yaitu Nomophobia Questionnaire (NMP-Q) dan UCLA Loneliness Scale (Version 3). Metode analisis menggunakan analisis deskriptif dan teknik product moment correlation untuk menguji hipotesis penelitian. Uji normalitas menggunakan Exploratory Data Analysis (EDA) dan uji linieritas menggunakan ANOVA test for linearity, kedua uji tersebut merupakan syarat untuk dapat melakukan uji hipotesis. Pengolahan data penelitian menggunakan program Statistical Package for Social Science (SPSS) version 22.00 for Windows.

\section{Nomophobia}

Variabel nomophobia diukur menggunakan Nomophobia Questionnaire (NMP-Q) yang disusun berdasarkan empat dimensi nomophobia oleh Yildirim dan Correia (2015), yaitu 
tidak dapat berkomunikasi (not being able to communicate), kehilangan keterhubungan (losing connectedness), tidak dapat mengakses informasi (not being able to access information), dan menyerah pada kemudahan (giving up convenience). NMP-Q berjumlah 20 butir dengan kategori butir positif (favorable) saja yang terdiri dari 7 alternatif jawaban. Total skor tertinggi sebesar 140 dan skor terendah 20. Penilaian NMP-Q terdiri dari 4 tingkatan, yaitu tidak ada nomophobia, nomophobia tingkat ringan, sedang, dan berat. Yildirim dan Correia menyebutkan nilai reliabilitas alpha Cronbach pada NMP-Q adalah sebesar 0,945.

\section{Kesepian}

Variabel kesepian diukur menggunakan skala yang dikembangkan dan disusun oleh Russell (1996). UCLA Loneliness Scale (Version 3) berjumlah 20 butir yang terdiri dari 11 butir positif (favorable) dan 9 butir negatif (unfavorable) dan yang terdiri dari 4 alternatif jawaban. Total skor tertinggi yaitu sebesar 80 dan skor terendah adalah 20. Penilaian UCLA Loneliness Scale (Version 3) terdiri dari 3 kategori, diantaranya kategori rendah, sedang, dan tinggi. Russell menyebutkan bahwa nilai reliabilitas alpha Cronbach pada UCLA Loneliness Scale (Version 3) sebesar 0,89 sampai dengan 0,94.

\section{Hasil}

\section{Data deskriptif}

Penelitian ini melibatkan mahasiswa perantau yang masih aktif kuliah di Universitas Syiah Kuala yang berasal dari luar Banda Aceh sebanyak 513 subjek dengan rentang usia 17-26 tahun. Subjek penelitian didominasi oleh jenis kelamin perempuan yaitu sebanyak $69,4 \%$, dan jumlah subjek laki-laki yaitu sebanyak 30,6\%. Mayoritas subjek penelitian ini berusia 17-20 tahun yaitu sebanyak 64\%. Pendidikan subjek didominasi oleh Strata Sarjana (S1) yaitu sebanyak 98,6\%, dan hanya 1,4\% dengan tingkat pendidikan Strata Magister (S2). Berdasarkan kategori status pekerjaan, subjek didominasi oleh subjek dengan status tidak bekerja yaitu sebanyak 96,7\%. Pada kategori tempat tinggal di Banda Aceh didominasi oleh subjek yang tinggal di kos/rumah sewa yaitu sebanyak 87,7\%. Ditinjau dari kategori lamanya merantau ke Banda Aceh, mayoritas subjek telah tinggal di Banda Aceh selama $>2$ tahun yaitu sebanyak 53,4\%. Subjek didominasi oleh subjek yang berasal dari Aceh yaitu sebanyak 78,6\%. Data demografi subjek dalam penelitian ini dapat dilihat pada Tabel 1. 


\section{Tabel 1}

Data Demografi Subjek Penelitian

\begin{tabular}{|c|c|c|}
\hline Deskripsi & Jumlah $(N)$ & Persentase (\%) \\
\hline \multicolumn{3}{|l|}{ Jenis Kelamin } \\
\hline Laki-Laki & 157 & 30,6 \\
\hline Perempuan & 356 & 69,4 \\
\hline \multicolumn{3}{|l|}{ Usia } \\
\hline 17-20 tahun & 328 & 64 \\
\hline 21-26 tahun & 185 & 36 \\
\hline \multicolumn{3}{|l|}{ Strata Pendidikan } \\
\hline S1 (Sarjana) & 506 & 98,6 \\
\hline S2 (Magister) & 7 & 1,4 \\
\hline \multicolumn{3}{|l|}{ Status Pekerjaan } \\
\hline Bekerja & 22 & 4,3 \\
\hline Tidak Bekerja & 491 & 95,7 \\
\hline \multicolumn{3}{|c|}{ Tempat Tinggal di Banda Aceh } \\
\hline Kos/Rumah Sewa & 450 & 87,7 \\
\hline Asrama & 63 & 12,3 \\
\hline \multicolumn{3}{|c|}{ Lama Merantau ke Banda Aceh } \\
\hline$<6$ Bulan & 68 & 13,3 \\
\hline$<2$ Tahun & 171 & 33,3 \\
\hline$>2$ Tahun & 274 & 53,4 \\
\hline \multicolumn{3}{|l|}{ Asal Daerah } \\
\hline Aceh & 403 & 78,6 \\
\hline Banten & 5 & 1,0 \\
\hline DKI Jakarta & 3 & 0,6 \\
\hline Jambi & 2 & 0,4 \\
\hline Jawa Barat & 3 & 0,6 \\
\hline Jawa Timur & 1 & 0,2 \\
\hline Lampung & 1 & 0,2 \\
\hline Papua & 1 & 0,2 \\
\hline Riau & 13 & 2,5 \\
\hline Sumatra Barat & 19 & 3,7 \\
\hline
\end{tabular}

\section{Kategorisasi Hasil Penelitian}

Kategorisasi variabel kesepian dan nomophobia pada mahasiswa perantau dapat dilihat pada Tabel 2. 
FAHIRA et al. | | KESEPIAN DAN NOMOPHOBIA

\section{Tabel 2}

Kategorisasi Kesepian dan Nomophobia pada Mahasiswa Perantau di Universitas Syiah Kuala

\begin{tabular}{llll}
\hline Variabel & Kategorisasi & Jumlah & Persentase (\%) \\
\hline Kesepian & Rendah & 378 & 73,7 \\
& Sedang & 106 & 20,7 \\
& Tinggi & 29 & 5,7 \\
Nomophobia & Tidak ada & 0 & 0 \\
& Ringan & 28 & 5,5 \\
& Sedang & 283 & 55,2 \\
& Berat & 202 & 39,4 \\
\hline
\end{tabular}

Berdasarkan Tabel 2, diketahui bahwa sebanyak 73,7\% subjek berada pada kategori kesepian rendah, 20,7\% subjek berada pada kategori kesepian sedang, dan 5,7\% subjek berada pada kategori kesepian tinggi. Kategorisasi nomophobia dapat diketahui bahwa tidak ada subjek dengan kategori "tidak ada nomophobia", 5,5\% subjek berada pada kategori nomophobia ringan, 55,2\% subjek berada pada kategori nomophobia sedang, dan $39,4 \%$ subjek berada pada kategori nomophobia tinggi.

\section{Uji Asumsi}

Uji asumsi dalam penelitian ini terdiri dari dua uji, yaitu uji normalitas dan uji linieritas. Uji normalitas menggunakan teknik Exploratory Data Analysis (EDA) bahwa variabel nomophobia menunjukkan nilai kurtosis $=-0,10$ dan nilai skewness $=-0,32$, sedangkan variabel kesepian menunjukkan nilai kurtosis $=-0,23$ dan nilai skewness $=0,15$. Data dikatakan normal dengan menggunakan analisis EDA jika nilai kurtosis dan skewness tidak melebihi $\pm 1,96$ (Howell, 2010). Hasil uji normalitas menggunakan teknik Exploratory Data Analysis menunjukkan bahwa data berdistribusi normal.

Hasil uji linieritas menggunakan ANOVA test for linearity menunjukkan bahwa Nomophobia Questionnaire (NMP-Q) dengan UCLA Loneliness Scale (Version 3) memiliki nilai signifikansi $p=0,034(p<0,05)$. Nilai signifikansi yang berada di bawah 0,05 dapat diartikan bahwa adanya hubungan linier antara variabel kesepian dengan nomophobia.

\section{Uji Statistik}

Analisis menggunakan teknik Pearson Product Moment menunjukkan hasil bahwa koefisien korelasi sebesar $r=0,094$ dan nilai signifikansi $(p)=0,034(p<0,05)$. Hasil tersebut dapat diartikan bahwa terdapat hubungan positif yang signifikan antara kesepian dengan nomophobia pada mahasiswa perantau di Universitas Syiah Kuala.

Hasil uji analisis dengan teknik Pearson Product Moment juga menunjukkan bahwa besaran nilai koefisien determinasi ( $R$ Squared) yaitu 0,009, hal ini dapat diartikan bahwa kesepian hanya berkontribusi terhadap nomophobia sebanyak 0,9\%, sedangkan 99,1\% lainnya dipengaruhi oleh variabel lain yang tidak dijelaskan di dalam penelitian ini. 
Selain itu, koefisien korelasi penelitian juga menunjukkan korelasi yang lemah, yaitu sebesar $r=0,094$.

Hasil uji analisis komponen nomophobia terhadap kesepian menggunakan teknik Pearson Product Moment dapat dilihat pada Tabel 3 yang menunjukkan bahwa hanya komponen giving up convenience dan kesepian yang memiliki hubungan signifikan dikarenakan nilai signifikansi $(p)=0,000$, yaitu berada di bawah $0,05(p<0,05)$.

\section{Tabel 3}

Uji Analisis Komponen Nomophobia terhadap Kesepian

\begin{tabular}{lccc}
\multicolumn{1}{c}{ Komponen Nomophobia } & $(p)$ & $(r)$ & Keterangan \\
\hline Not being able to communicate & 0,255 & 0,050 & Tidak Signifikan \\
Losing connectedness & 0,132 & 0,067 & Tidak Signifikan \\
Not being able to access information & 0,351 & 0,041 & Tidak Signifikan \\
Giving up convenience & 0,000 & 0,160 & Signifikan \\
\hline
\end{tabular}

\section{Diskusi}

Penelitian ini dilakukan bertujuan untuk mengetahui hubungan antara kesepian dan nomophobia pada mahasiswa perantau di Universitas Syiah Kuala. Hasil analisis menunjukkan bahwa hipotesis diterima, dapat diartikan bahwa terdapat hubungan positif antara kesepian dengan nomophobia pada mahasiswa perantau di Universitas Syiah Kuala.

Hasil penelitian ini serupa dengan penelitian Kara et al. (2019) yang menunjukkan bahwa tingginya perasaan kesepian pada individu cenderung meningkatkan nomophobia, hal ini disebabkan oleh adanya usaha untuk mengurangi rasa kesepian dengan mengalihkannya pada smartphone sehingga dapat menimbulkan ketakutan dan gelisah ketika tidak dapat menggunakan smartphone.

Adanya hubungan kesepian dan nomophobia pada mahasiswa perantau di Universitas Syiah Kuala dalam penelitian ini dapat juga dijelaskan berdasarkan tinjauan teori operant conditioning yang dipopulerkan oleh Skinner. Operant conditioning melibatkan pengendalian konsekuensi yang terdiri dari hadiah (reward) yaitu memberikan sesuatu yang diinginkan individu dengan tujuan perilaku yang diharapkan dapat diulangi, dan hukuman (punishment) yaitu memberikan sesuatu yang tidak diinginkan individu dengan tujuan perilaku yang tidak diharapkan tidak diulangi (Feist et al., 2013). Dalam penelitian ini, dapat dikaitkan bahwa mahasiswa perantau yang kesepian cenderung melakukan pengalihan dengan cara menghubungi kerabat dan berinteraksi dengan orang lain menggunakan smartphone, upaya tersebut memberikan rasa nyaman dan mengurangi kesepian (reward) ketika menggunakan aplikasi dan fitur yang ditawarkan smartphone, sehingga individu terus melakukan pengalihan karena smartphone membantu mengurangi 
kesepian. Namun demikian, kebiasaan menggunakan smartphone sebagai pengalihan secara terus-menerus dapat memicu munculnya nomophobia (Darcin et al., 2016; Stephanie \& Pristinella, 2014).

Berdasarkan pengelompokan kategorisasi, secara umum menunjukkan bahwa kesepian pada mahasiswa perantau di Universitas Syiah Kuala berada pada tingkat rendah, sedangkan nomophobia berada pada tingkat sedang. Hasil kategorisasi menunjukkan bahwa sebanyak $73,7 \%$ subjek berada pada tingkatan kesepian rendah, Prasetya dan Hartati (2015) mendeskripsikan individu dengan tingkat kesepian yang rendah sebagai individu yang memiliki kesiapan dan keberanian membangun hubungan dengan orang lain dan didukung oleh keterampilan komunikasi yang baik sehingga mampu menjalin hubungan akrab dengan orang lain.

Hasil kategorisasi juga menunjukkan bahwa sebanyak 20,7\% subjek berada pada tingkatan kesepian sedang. Doryab et al. (2019) menggambarkan perilaku yang ditunjukkan individu seperti cenderung aktif menggunakan smartphone pada malam hari dan waktu belajar lebih sedikit saat hari libur.

Hasil kategorisasi menunjukkan bahwa sebanyak 5,7\% subjek berada pada tingkatan kesepian tinggi. Gao et al. (2016) menjelaskan bahwa tingkat kesepian yang tinggi ditunjukkan dengan perilaku seperti penelusuran web (browsing) yang berlebihan, menggunakan aplikasi tertentu, dan lebih sering mengakses media sosial.

Secara umum, pengelompokan kategorisasi nomophobia pada mahasiswa perantau di Universitas Syiah Kuala berada pada tingkat sedang. Hasil kategorisasi menunjukkan bahwa sebanyak 55,2\% subjek berada pada tingkatan nomophobia sedang, individu dengan tingkat nomophobia sedang menunjukkan perilaku berupa cukup sering menggunakan smartphone, yaitu kurang dari 2 sampai dengan 3 jam sekali (Kanmani et al., 2017; Prasetyo \& Ariana, 2015).

Hasil kategorisasi juga menunjukkan bahwa sebanyak 39,4\% subjek berada pada tingkatan nomophobia berat, perilaku individu dengan tingkat nomophobia berat seperti menggunakan smartphone selama 24 jam (bahkan ketika akan tidur), tidak pernah mematikan smartphone, dan menggunakannya pada saat yang tidak sesuai, seperti ketika mandi, makan, dan berkendara (Ali et al., 2017; Dixit et al., 2010; Gezgin, 2017; Kanmani et al., 2017; Pavithra et al., 2015;).Hasil kategorisasi menunjukkan bahwa sebanyak 5,5\% subjek berada pada tingkatan nomophobia rendah, individu dengan tingkat nomophobia rendah menggunakan smartphone hanya ketika dibutuhkan, yaitu selama 1 sampai dengan 2 jam sehari (Pavithra et al., 2015; Prasetyo \& Ariana, 2016).

Penelitian ini juga menunjukkan hasil bahwa keterkaitan dua variabel dari kesepian dan nomophobia memiliki hubungan yang lemah ataupun rendah. Hasil uji determinasi menunjukkan bahwa pengaruh variabel kesepian terhadap nomophobia pada mahasiswa perantau di Universitas Syiah Kuala hanya sebesar 0,9\%, sedangkan 99,1\% lainnya dipengaruhi oleh faktor yang tidak diteliti dalam penelitian ini. Keterkaitan variabel kesepian dan nomophobia yang rendah dapat dijelaskan berdasarkan hasil uji 
analisis tambahan yang dilakukan oleh peneliti yaitu dengan menguji komponen nomophobia terhadap kesepian.

Hasil analisis tambahan tersebut, menunjukkan bahwa hanya komponen giving up convenience (perasaan nyaman karena menggunakan smartphone) yang berhubungan dengan kesepian. Adanya hubungan yang signifikan antara kesepian dengan komponen giving up convenience dapat diartikan bahwa kesepian pada mahasiswa perantau memicu munculnya nomophobia yang disebabkan oleh adanya perasaan nyaman ketika menggunakan smartphone sebagai pengalihan dari rasa kesepian. Hal ini didukung oleh pernyataan Song et al. (2004) yang menjelaskan bahwa smartphone memberi kenyamanan sebagai penguatan (reinforcement) sehingga membuat individu terus menggunakannya.

Berdasarkan hasil analisis tambahan juga menunjukkan bahwa tiga komponen nomophobia lainnya, yaitu not being able to communicate, losing connectedness, dan not being able to access information tidak berkorelasi dengan kesepian, sehingga hal ini menjadi salah satu penyebab rendahnya hubungan kesepian terhadap nomophobia pada mahasiswa perantau di Universitas Syiah Kuala. Rendahnya hubungan antara kesepian terhadap nomophobia dalam penelitian ini juga dapat dijelaskan oleh faktor kondisi lamanya merantau, di mana sampel didominasi oleh subjek yang telah lama merantau dan tinggal di Banda Aceh selama >2 tahun. Kondisi lamanya individu merantau memengaruhi tingkat kesepian yang disebabkan oleh kemampuan individu mengatasi masalah dan penyesuaian diri yang baik (Sears et al., 1985). Hal ini juga didukung oleh penjelasan Prasetya dan Hartati (2015) yang mengatakan keberhasilan dalam menyesuaikan diri dengan lingkungan baru memunculkan rasa dimengerti, dipercaya, berguna dan berharga, sehingga individu terhindar dari rasa kesepian.

\section{Kesimpulan}

Tujuan dilakukannya penelitian ini yaitu untuk mengetahui hubungan antara kesepian dan nomophobia. Hasil penelitian menemukan bahwa terdapat hubungan positif yang signifikan antara kesepian dan nomophobia pada mahasiswa perantau di Universitas Syiah Kuala, dapat diartikan bahwa semakin tinggi tingkat kesepian maka semakin tinggi tingkat nomophobia pada mahasiswa perantau. Sebaliknya, semakin rendah tingkat kesepian, maka semakin rendah pula tingkat nomophobia pada mahasiswa perantau.

Hasil uji determinasi menunjukkan bahwa pengaruh variabel kesepian terhadap variabel nomophobia pada mahasiswa perantau di Universitas Syiah Kuala adalah sangat rendah, yaitu hanya 0,9\%. Hasil penelitian juga menunjukkan bahwa tingkat kesepian mahasiswa perantau di Universitas Syiah Kuala (Unsyiah) berada pada kategori rendah dan tingkat nomophobia berada pada kategori sedang. 


\section{Saran}

Hasil penelitian ini diharapkan menjadi bahan pertimbangan bagi pihak institusi yaitu Universitas Syiah Kuala untuk dapat membuat survei sehingga mahasiswa yang mengalami nomophobia sedang dan berat dapat diberikan bantuan psikologis seperti mengikuti treatment dari para psikolog di Unit Pelayanan Konseling dan Psikologi Terpadu (UPKPT) Unsyiah. Peneliti selanjutnya yang ingin mengkaji variabel yang sama dengan penelitian ini (replikasi) disarankan menggunakan metode kualitatif melalui observasi dan wawancara agar mendapatkan data secara mendalam. Selain itu, disarankan juga bagi peneliti selanjutnya untuk mengkaji variabel nomophobia dengan beberapa variabel psikologi lain yang tidak dijelaskan secara mendalam pada penelitian ini, khususnya variabel-variabel psikologi sosial, psikologi perkembangan, dan psikologi pendidikan.

\section{Ucapan Terima Kasih}

Peneliti mengucapkan terima kasih kepada Ibu Zaujatul Amna, S.Psi., M.Sc., Ibu Dr. Marty Mawarpury, M. Psi., Psikolog, Ibu Syarifah Faradina, S.Psi, M.Psi Psikolog, dan seluruh mahasiswa perantau Universitas Syiah Kuala yang telah bersedia menjadi responden penelitian.

\section{Kontribusi Penulis}

ZF merancang penelitian, menganalisis data, dan mengedit naskah. ZA, MM, dan SF membaca, mengedit, dan menyetujui versi final naskah.

\section{Konflik Kepentingan}

Para penulis menyatakan bahwa tidak terdapat konflik kepentingan di dalam penelitian, penulisan, dan/atau publikasi artikel ini.

\section{Kepustakaan}

Ali, A., Ridzuan, A. R., Muda, M., Nuji, M. N. N., Izzamuddin, M. H. M., \& Latif, D. I. A. L. (2017). The relationship between phone usage factors and nomophobia. American Scientific Publisher, 1-5. https://doi.org/10.1166/asl.2017.9534

Bian, M., \& Leung, L. (2014). Linking loneliness, shyness, smartphone addiction symptoms, and patterns of smartphone use to social capital. Social Science Computer Review, 33(1), 61-79. https://doi.org/10.1177/0894439314528779

Darcin, A. E., Kose, S., Noyan, C., Nurmedov, S., Yilmaz, O., \& Dilbaz, N. (2016) Smartphone addiction in relation with social anxiety and loneliness. Behavior $\mathcal{E}$ Information Technology. https://doi.org/10.1080/0144929X.2016.1158319

Dewi, R. L. (2016). Hubungan attachment style dengan penyesuaian perguruan tinggi mahasiswa perantau pendidikan kedokteran Unsyiah [Skripsi tidak dipublikasikan]. Universitas Syiah Kuala.

Dixit, S., Shukla, H., Bhagwat, A. K., Bindal, A., Goyal, A., Zaidi, A. K., \& Shrivastava, A. (2010). A study to evaluate mobile phone dependence among students of a 
medical college and associated hospital of central India. Indian Journal of Community Medicine, 35(2). https://doi.org/10.4103/0970-0218.66878

Doryab, A., Villalba, D. K., Chikersal, P., Dutchter, J. M., Tumminia, M., Liu, X., Cohen, S., Creswell, K., Mankoff, J., Creswell, J. D., Dey, A. K. (2019). Identifying behavioral phenotypes of loneliness and social isolation with passive sensing: Statistical analysis, data mining, and machine learning of smartphone and fitbit data. JMIR Mhealth and Uhealt, 7(7), 1-19. https://doi.org/10.2196/13209

Feist, J., Feist, G. J., \& Roberts, T. A. (2013). Theories of personality ( $8^{\text {th }}$ ed.). McGraw-Hill.

Fitriana, R. (2018). Pengaruh penggunaan instant messenger terhadap kecenderungan perilaku nomophobia (studi terhadap mahasiswa Universitas Syiah Kuala Banda Aceh) [Skripsi tidak dipublikasikan]. Universitas Syiah Kuala.

Gao, Y., LI, A., Zhu, T., Liu, X., \& Liu, X. (2016). How smartphone usage correlates with social anxiety and loneliness. PeerJ, 4. https://doi.org/10.7717/peerj.2197

Gezgin, D. M. (2017). Exploring the influence of the patterns of mobile internet use on university students' nomophobia level. European Journal on Education Studies, 3(6), 29-52. https://doi.org/10.5281/zenodo.572344

Gezgin, D. M., Hamutoglu, N. D., Sezen, G. G., \& Ayas, T. (2018). The relationship between nomophobia and loneliness among Turkish adolescents. International Journal of Research in Education and Science, 4(2), 358-374. https://doi.org/10.21890/ijres.409265

Hidayati, D. S. (2016). Self compassion dan loneliness. Jurnal Ilmiah Psikologi Terapan, 3(1), 154-164. https://doi.org/10.22219/jipt.v3i1.2136

Howell, D. C. (2010). Statistical methods for psychology. Wadsworth.

Kanmani, S. A., Bhavani, U. \& Maragatham, R. S. (2017). Nomophobia-an insight into its psychological aspects in India. The International Journal of Indian Psychology, 4(2), 515. https://doi.org/10.25215/0402.041

Kara, M., Baytemir, K., \& Inceman-Kara, F. (2019) Duration of daily smartphone usage as an antecedent of nomophobia: exploring multiple mediation of loneliness and anxiety. Behaviour $\mathcal{E}$ Information Technology. https://doi.org/10.1080/0144929X.2019.1673485

King, A. L. S., Valenca, A. M., \& Nardi, A. E. (2010). Nomophobia: The mobile phone in panic disorder with agoraphobia: Reducing phobias or worsening of dependence? Cognitive and Behavioral Neurology, 23(1), 52-54. https://doi.org/10.1097/WNN.0b013e3181b7eabc

Leung, L. (2008). Linking psychological attributes to addiction and improper use of the mobile phone among adolescents in Hong Kong. Journal of Children and Media, 2(2), 93-113. https://doi.org/10.1080/17482790802078565

Mansyur, A. S. (2018). Identifikasi tingkat no mobile phone phobia (nomophobia) di Aceh [Skripsi tidak dipublikasikan]. Universitas Syiah Kuala.

Nejad, S, B, Pak, S., \& Zarghar, Y. (2013). Effectiveness of social skills training in homesickness, social intelligence and interpersonal sensitivity in female university student resident in dormitory. International Journal of Psychology and Behavioral Research, 2(3), 168-175. https://rms.scu.ac.ir/Files/Articles/Journals/Abstract/Intl.-J.Phys.-Beh.-Res.-Vol.-23-168-175-2013.pdf201312301130831.pdf

Özdemir, B., Cakir, O., \& Hussain, I. (2018). Prevalence of nomophobia among university students: A comparative study of Pakistani and Turkish undergraduate students. 
EURASIA Journal of Mathematics, Science and Technology Education, 14(4), 1519-1532. https://doi.org/10.29333/ejmste/84839

Pavithra, M. B., Madhukumar, S., \& Murthy, M. T. S. (2015). A study on nomophobia mobile phone dependence, among students of a medical college in Bangalore. National Journal of Community Medicine, 6(2), 340-344. http://njcmindia.org/uploads/6-3 340-344.pdf

Peplau, L. A., \& Perlman, D. (1982). Loneliness: A sourcebook of current theory, research, and therapy. Wiley-Interscience.

Prasetya, D. N., \& Hartati, M. S. (2015). Hubungan antara kesepian dan penyesuaian diri pada mahasiswa (studi korelasi pada mahasiswa tahun pertama Fakultas Psikologi Universitas Diponegoro). Jurnal Empati, 3(1), 47-56. https://ejournal3.undip.ac.id/index.php/empati/article/view/7479

Prasetyo, A, \& Ariana, A. D. (2016). Hubungan antara the big five personality dengan nomophobia pada wanita dewasa awal. Jurnal Psikologi Klinis dan Kesehatan Mental, 5(1), 1-9. http://journal.unair.ac.id/download-fullpapers-jpkk0a021ea3452full.pdf

Ramaita, R., Armaita, A., \& Vandelis, P. (2019). Hubungan ketergantungan smartphone dengan kecemasan (nomophobia). Jurnal Kesehatan, 10(2), 89-93. https://doi.org/10.35730/jk.v10i2.399

Ridha, A. A. (2018). Task commitment pada mahasiswa suku Bugis yang merantau. Jurnal Psikologi, 45(1), 66-76. https://doi.org/10.22146/jpsi.31094

Russell, D. W. (1996). UCLA Loneliness Scale (version 3): Reliability, validity and factor structure. Journal of Personality Assesment, 66, 20-40. https://doi.org/10.1207/s15327752jpa6601_2

Saputri, N. S., Rahman, A. A., \& Kurniadewi, E. (2012). Hubungan antara kesepian dengan konsep diri mahasiswa perantau asal Bangka yang tinggal di Bandung. Psympathic, Jurnal Ilmiah Psikologi, 5(2), 645-653. https://doi.org/10.15575/psy.v5i2.2158

Sears, D. O., Freedman, J. L., \& Peplau, L. A. (1985). Social Psychology (5 ${ }^{\text {th }}$ ed.). PrenticeHall.

SecurEnvoy. (2012, 16 Februari). 66\% of the population suffer from nomophobia the fear of being without their phone. https://www.securenvoy.com/en-gb/blog/66-population-suffernomophobia-fear-being-without-their-phone

Song, I., Larose, R., Eastin, M. S., \& Lin, C. A. (2004). Internet gratifications and internet internet addiction: On the uses and abuses of new media. CyberPsychology Behavior, 7(4), 384-394. https://doi.org/10.1089/cpb.2004.7.384

Stephanie, S., \& Pristinella, D. (2014). Hubungan antara jenis kepribadian agreeableness, openness, dan conscientiousness dengan kecenderungan ketergantungan mahasiswa pada telepon seluler. Jurnal Penelitian, 18(1), 9-18. https://ejournal.usd.ac.id/index.php/JP/article/view/801

Yildirim, C., \& Correia, A. P. (2015). Exploring the dimensions of nomophobia: Development and validation of a self-reported questionnaire. Computers in Human Behavior, 49, 130-137. https://doi.org/10.1016/j.chb.2015.02.059

Yuwanto, L. (2010). Mobile phone addict. Putra Media Nusantara. 